\title{
An action-research exploration of value chain development from field to consumer based on organic hempseed oil in Sicily ${ }^{\text {is }}$
} \author{
Kevin Morel $^{5}$ \\ ${ }^{1}$ FIRAB, Fondazione Italiana per la Ricerca in Agricoltura Biologica e Biodinamica, Rome, Italy \\ 2 CREA, Research Centre for Agricultural Policies and Bioeconomy, Palermo, Italy \\ ${ }^{3}$ CREA, Research Centre for Agriculture and Environment, Rome, Italy \\ ${ }^{4}$ SyTra, Earth and Life Institute, UCLouvain, Louvain-la-Neuve, Belgium \\ ${ }^{5}$ UMR SADAPT, INRAE, AgroParisTech, Université Paris-Saclay, Paris, France
}

Luca Colombo $^{1, *}$, Giovanni Dara Guccione ${ }^{2}$, Stefano Canali ${ }^{3}$, Ileana Iocola ${ }^{3}$, Clémentine Antier ${ }^{4}$ and

Received 9 March 2020 - Accepted 15 September 2020

\begin{abstract}
Although hemp cultivation is increasingly perceived as a promising option in terms of crop diversification, especially in semi-arid conditions such as in the Mediterranean region, its adoption remains limited thus constraining the development of hemp value chains at a larger scale. Our objective was to explore suitable conditions, at farm and downstream levels, for organic hempseed oil production in Sicily, taking on an action-research perspective that involves local actors. Based on a preliminary characterisation of barriers to organic hemp development at different value chain levels, we carried out targeted complementary investigation: (i) assessment on agroenvironmental performances of integrating hemp in durum wheat-based rotations; (ii) chemical analysis of local hempseed oil; (iii) exploration of marketing opportunities and value chain development. Our results showed that the lack of technical and economic knowledge as well as the deficiencies of suitable cultivars and adequate machinery were the main barriers for the organic hemp value chain development in Sicily. The analysis of agroenvironmental performances also revealed both strengths and weaknesses of hemp introduction in durum-wheat based rotations. Despite the identified limitations, we demonstrated that the organic hemp value chains represent interesting perspectives for the Sicilian farming sector, particularly in case of substantial barriers removal or adaptation.
\end{abstract}

Keywords: barriers to market development / Cannabis sativa L / co-innovation / crop diversification / hemp food value chains / organic hempseed oil

Résumé - Réintroduire le chanvre en Sicile : exploration par recherche-action du développement d'une chaîne de valeur du champ au consommateur pour l'huile biologique. Bien que la culture de chanvre soit perçue de manière croissante comme une option prometteuse pour la diversification des cultures, en particulier en conditions semi-arides dans la zone méditerranéenne, le développement à large échelle de chaines de valeur pour le chanvre est encore limité. Notre objectifétait d'explorer les conditions adéquates pour l'exploitation de l'huile de chanvre biologique en Sicile au niveau de la ferme et de l'aval. Nous avons opté pour une perspective de recherche-action mobilisant des acteurs locaux. À partir d'une caractérisation préliminaire des freins au développement du chanvre biologique en Sicile à différents maillons de la chaîne de valeur, nous avons mené des recherches complémentaires ciblées : (i) évaluation des performances agroenvironnementales de l'intégration du chanvre dans des rotations à base de blé dur, (ii) analyse chimique de l'huile de chanvre locale, (iii) exploration des opportunités en termes de commercialisation et développement de chaîne de valeur. Nos résultats montrent des perspectives intéressantes pour les chaînes de valeur de chanvre biologique en Sicile avec une rentabilité prometteuse, en particulier si les freins les plus importants sont levés ou des adaptations trouvées. L'étude a également mis en lumière des points clés à considérer pour un développement futur du chanvre.

Mots clés : chaîne de valeur pour le chanvre alimentaire / co-innovation / diversification des cultures / freins au développement de marché / huile de chanvre biologique

\footnotetext{
Contribution to the Topical Issue "Organic foods in the oil \& protein

crop supply chain / Le «Bio» dans la filière oléoprotéagineuse".

*Correspondence: 1.colombo@firab.it
} 


\section{Introduction}

The area of hemp (Cannabis sativa L.) cultivated in Europe has increased from 15,700 ha in 2013 to 46,600 in 2017, with a further growth expected for the current decade, mainly driven by the mounting demand for hemp seed by the food market (Foti et al., 2019). In Italy, the 2018 acreage was estimated close to 4000 ha (Coldiretti, 2019), mostly devoted to the food and para-pharmaceutical sectors, after decades of neglect (one century ago, Italy was the second largest hemp producer in the world after Russia, reaching 120,000 ha, supplying the fibre industries). The current rediscover may lead to a wide-ranging exploration of agroecological options and to reorient cultivars selection, as the increased commercial interest for hemp in food products and a somewhat clearer legal status have stimulated a reorientation toward harvesting hemp grain as the main produce instead of biomass (Baldini et al., 2018).

Hemp-based foods arise from an assortment of grain and flower uses (food preparations based on hemp flour, hemp oil, beers that blend hemp inflorescences with hop) derived from non-psychoactive cultivars. Hemp oil is produced by simple pressing of seeds and is authorised in the food market under the existing regulation, provided that Tetrahydrocannabinol (THC) content be below $5.0 \mathrm{mg} \mathrm{kg}^{-1}\left(2.0 \mathrm{mg} \mathrm{kg}^{-1}\right.$ for grains and flour) (Ministry of Health, 2000). Several clinical trials have identified hempseed oil as a functional food attributed to high levels of Essential Fatty Acid (EFAs) and other Polyunsaturated Fatty Acids (PUFAs). Hempseed oil is over $80 \%$ in PUFAs and, in terms of EFAs, it is an exceptionally rich source of linoleic acid (omega-6; ranging between 50-70\%) and $\alpha$-linolenic acid (omega-3; 15-25\%). The omega-6 to omega-3 ratio (n-6/n-3) in hempseed oil generally ranges between $2: 1$ and $3: 1$, which is considered optimal for human health (Callaway, 2004). Besides fatty acids, moderate to high vitamin $\mathrm{E}$ concentrations are present in hemp oil as well as remarkable amounts of phytosterols, phospholipids, chlorophyll, carotenes, and several minerals (Sapino et al., 2005).

In Sicily, where conditions are semi-arid, hemp seems to be a promising option to diversify durum wheat-based (Triticum durum) cropping systems in terms of both the agronomic role in the crop rotation (limited water requirements, weed suppression capacity) and food value chains opportunities, thus potentially contributing to increase the environmental and economic performance of local food systems (Lin, 2011; Lundgren and Fausti, 2015). Besides that, being organic agriculture a strategic sector in Sicily with 385,356 ha certified under the EU organic regulation, equivalent to $26,8 \%$ of the regional agriculture utilised area (UAA) (SINAB, 2019), organic hemp, and specifically organic hemp oil, may strengthen the organic market potential as it responds to the increasing demand for nutrient-rich foods and health-related products (de Magistris and Gracia, 2008).

Despite the above-mentioned potential benefits, developing organic hempseed oil in Sicily seems to face a number of barriers and, at present, a very limited part of this organic area is currently devoted to hemp, whose overall regional area (under either conventional or organic systems) is estimated around 600 ha in 2019 , representing only $0.04 \%$ of the Sicilian UAA (compared to 263,525 ha of regional durum wheat area, equivalent to ca. $20 \%$ of the Sicilian UAA; ISTAT database). As no recent figures are officially available on the Sicilian hemp acreage, the estimations on the scale of hemp adoption rely on information provided by some interviewed local farmers pioneering hemp cultivation and related local hemp chains, who assumed that about 500 ha of hemp were cultivated under contracts for para-pharmaceutical uses ${ }^{1}$, while more than 100 ha were cultivated for food production (mainly oil and flour), mostly farmed organic (Antier et al., 2019).

Transition toward more diversified food systems is indeed hindered by a situation of socio-technical lock-in, which means that various interdependent barriers to crop diversification exist at different levels of the food systems (from field to plate) and reinforce each other (David, 1985; Vanloqueren and Baret, 2008; Magrini et al., 2016; Meynard et al., 2018). Overcoming this lock-in situation requires to identify and tackle the related barriers at all levels of food systems (Meynard et al., 2016). Building on that perspective, a participatory research-action approach (Chevalier and Buckles, 2019) was implemented in Sicily within the framework of the Horizon 2020 DiverIMPACTS $^{2}$ project. This approach relied on a multidimensional and multiactorial investigation developed to assess to which conditions hemp cultivation and value chains may result viable in the Sicilian context in a re-habilitating legislative and market momentum. Our research objective was thus to explore suitable conditions for on-farm and downstream exploitation of hempseed oil, in a farming diversification context where organic certification may offer additional value to produce. This multifaceted journey was carried out in 2018 and 2019 involving local actors in a co-innovation dynamic, focusing on aspects considered as supportive of the hemp value chain development when at its infancy. Moving from farm to market, this study required the following targeted investigations that, simultaneously carried out, were in detail aimed to:

- characterise the main barriers that hamper hemp cultivation and value chain development, considering the substantial past freeze of the crop;

- evaluate the agroecological implications originating from the hemp integration in the farm rotation to assess the environmental profile of the crop in semi-arid conditions;

- assess the basic chemical characteristic of the Sicilian hempseed oil related to its nutritional features, testing its properties vis-à-vis equivalent products;

- explore the hempseed oil market profitability and potential industrial development to understand at which competitive conditions the Sicilian products can be sold at domestic and European scale.

\section{Material and methods}

The Horizon 2020 DiverIMPACTS project aims to foster crop diversification in Europe. It promotes participatory research approaches (Chevalier and Buckles, 2019) on 25 case studies (CS) in 11 countries, exploring a range of possible spatial and temporal diversification solutions through

\footnotetext{
${ }^{1}$ Especially under contract with Canopy Growth Corp: https://www. canopygrowth.com.

${ }^{2}$ https://www.diverimpacts.net.
} 
a kaleidoscope of context-related activities. The 25 DiverIMPACTS's CSs have been developed following a common methodology in relation to their modus operandi and monitoring activities. To achieve diversification from field to plate, relying on a transition of the whole food system, the project fostered a multi-actor co-innovation process. The global theory of action of such approach was to involve different value chain actors in the initial diagnosis of the situation, in the expression of a common vision and objectives to achieve and in the design of an action plan to fulfil objectives (Bos and Grin, 2012; Elzen et al., 2012). This approach is inspired by reflexive monitoring in action for learning (Van Mierlo et al., 2010) and reflexive interactive design inspired by the Dutch RIO approach (Bos and Grin, 2012). As innovation is a dynamic process, the definition of objectives, actors involved and action plan is iterative, based on constant monitoring of progress achieved, evolving perception of barriers and opportunities informed by action and discussion with actors (Geels and Schot, 2007; Grin et al., 2010; Klerkx et al., 2010). Operationally, each CS was led and monitored by an "innovation team" (CS team) in charge of stimulating collaboration between research bodies, farmers, farmers' organisations, associations, industries, businesses and public institutions.

The objective of the Sicilian CS was to identify optimal solutions for the diversification of arable systems in a semi-arid environment, in terms of agroecological and supply chain opportunities. It was composed of researchers (who coauthored this paper) belonging to the Italian Foundation for Research in Organic and Biodynamic Agriculture (FIRAB) and the Italian Council for Agricultural Research and Economics (CREA) and conventional, organic and transitioning-to-organic farmers considered as 'actors' (individuals and organizations that were closely involved in planning, decision making and experimenting in the CS). Starting from spring 2017 and leveraging on existing relationships, the CS team pooled together an initial nucleus of actors composed by the DiverIMPACTS researchers, one organic and one conventional farmer (both large-sized, with ca. 100 ha of arable area), an advisor in the area of organic farming, a seed supplier and other organic farmers interested in crop diversification processes. This group initially focused the attention on two combined aspects: how to improve the crop rotation sustainability through a better and greater leguminous crops integration while ensuring the farm profitability. Initially, consideration was devoted to crops like chickpea (Cicer arietinum $L$.) and sulla clover (Hedysarum coronarium L.) as points of departure for the diversification processes, subsequently deemed not ambitious enough (despite considered otherwise by some stakeholders) and potentially limited in consideration of the erratic demand and market prices for these leguminous crops. To broaden the CS mission and goals, the CS core group was enlarged at the beginning of the second year of the project with the integration of two additional farms (one partially organic on $100+$ ha of arable land and the other one transitioning to organic on its $10 \mathrm{ha}$ and also owning a mill). In those two farms, organic hemp was about to begin the third year of (still pioneering) cultivation thus providing the opportunity to act as living labs to study agroecological performances as well as downstream processing and commercialisation dynamics. Building knowledge on these two farms was deemed relevant for such exploratory research on a value chain at its infancy and also considered a pragmatic way of dealing with pioneer innovations (Siggelkow, 2007). To do so, we ensured that the two selected farms covered contrasted situations that could present some replicability conditions at Sicilian level in view of a regional scalability of practices, possibly instigating a greater change in the agricultural sector, in a logic of theoretical rather than statistical sampling (Eisenhardt, 1989).

Consequently, to grasp indications on the factors enabling and/or hindering hemp development in a context of crop and value chain diversification, the original CS action plan was opened to revision and to new considerations, mostly arising around the opportunity to more fully integrate hemp cultivation and value chain opportunities. In this paper, we will only focus on those aspects.

\subsection{Characterisation of barriers to organic hemp development in Sicily in a co-innovation dynamic context}

The first phase of the co-innovation approach was to involve the CS actors in the identification of the challenges they face. Barriers to organic hemp development in Sicily were characterised based on a qualitative and iterative inquiry procedure detailed in Morel et al. (2020). This approach can be briefly summarised by the following steps:

- in January 2018, a two-hour brainstorming was carried out with the CS team using the causal analysis method to realize an initial problem tree (Van Mierlo et al., 2010; AUSAID, 2005) for defining the main barriers related to organic hemp. This brainstorming was facilitated by a DiverIMPACTS scientist not directly involved in the Sicilian CS. It aimed at structuring all the material and knowledge informally collected by the CS team during their prior interactions with CS actors;

- this first overview of barriers was enriched by complementary one-hour semi-structured interviews led by the CS team with the CS actors (the CS hemp growers). Those interviews were carried out based on a set of topics and a structured data collection framework shared across DiverIMPACTS CSs (Morel et al., 2020) ensuring that all levels of the value chain were covered: (i) farmers and production, (ii) downstream operations from farm to retailing, (iii) marketing and consumers, (iv) contracts and coordination between actors;

- all the collected data were processed progressively through a method of qualitative analysis (Elo and Kyngäs, 2008) using the coding and matrix tools described by Miles and Huberman (1984). The general aim of this approach was to gradually organise the information gathered by the Sicilian CS team through discussions with the different value chain stakeholders along the co-innovation dynamic in a perspective of learning by doing.

\subsection{Assessing agroenvironmental performances of integrating hemp in durum wheat-based rotations}

The DiverIMPACTS project defined an original set of 32 indicators sensitive to crop diversification in order to monitor and assess the environmental, economic and social 


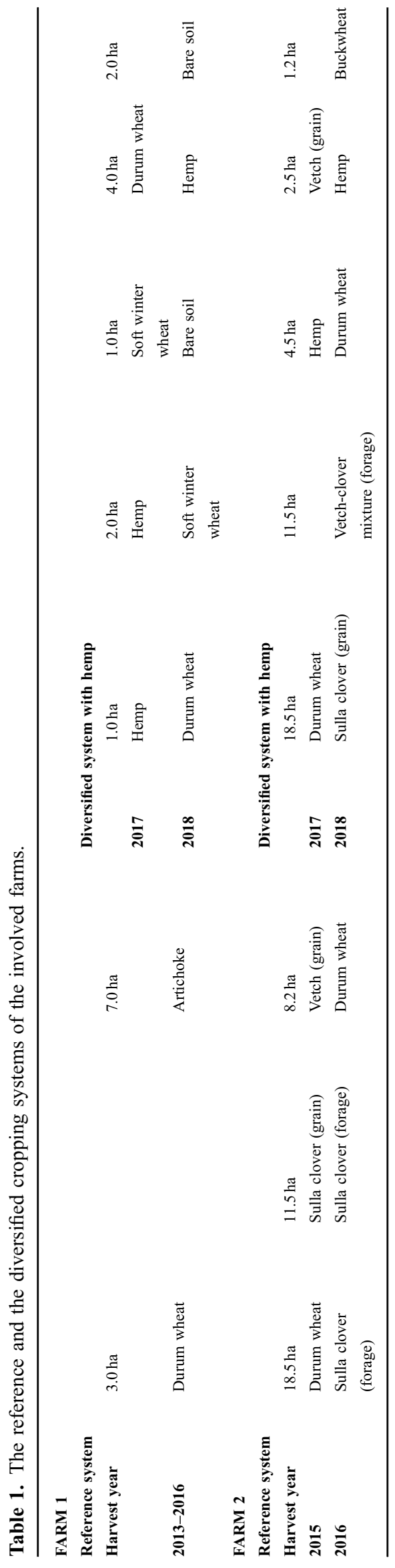

sustainability of the diversified cropping strategies implemented in the $25 \mathrm{CSs}$. The set of indicators was co-developed by integrating scientific knowledge and the CSs' actor perspectives and needs, which were integrated through interviews carried out during the first (2017) and second (2018) rounds of co-innovation workshops.

To grasp indications on the agroecological pertinence of hemp in rainfed Sicilian rotations, a subset of eight indicators was selected to assess the environmental performances of the CS's cropping systems. These indicators were carefully chosen as being the most suitable within the DiverIMPACTS assessment framework to reveal the effects of hemp introduction in the cropping system and to avoid redundancy with the complementary socio-economic analysis and explorations carried out in the CS. Moreover, as in addition to the introduction of hemp the two farms also moved to organic management, the indicators whose improvement was mainly determined by the organic conversion (i.e. pollution effects related to the use of synthetic fertilizer and plant protection products) rather than by the hemp introduction, were not included in the assessment.

A data collection excel file was designed to allow the CS team to collect data by face-to-face interviews with the hemp farmers. On average, two interviews were needed per farm of approximately two-three hours to collect all the required information. Data were collected taking into account pre(reference system) and post- diversification (diversified system with hemp) cropping systems (Tab. 1).

Data quality was checked by researchers and subsequently analysed. Formulas were implemented in the excel file to perform the computation of the following selected performance indicators: Energetic content of crop yields - EY (GJ/ha); Crop Diversity Index - CDI which combines species diversity and the proportion of each crop; Bare soil during drainage periods - BSO (\%); Annual Carbon input during the rotation - ACI ( $\mathrm{t} C / \mathrm{ha})$; Nitrogen and Phosphorus balances - NBAL (kg N/ha) and PBAL $\left(\mathrm{kg} \mathrm{P}_{2} \mathrm{O}_{5} / \mathrm{ha}\right)$; Global warming potential from total fuel consumption - FCFGHG ( $\mathrm{kg} \mathrm{CO}_{2}$ equiv./ha); Work overload - WOL (\%). The indicators were computed both at rotational and single-crop level. The values of indicators at rotational level were subsequently scaled to values between 0 and 10 (from 0 -worst to 10 - best performance) and returned in the form of a radar graph.

\subsection{Analysis of chemical composition of organic hemp}

The Sicilian hempseed oil has been assessed to test its quality and predisposition to marketing as a noteworthy functional food. Chemical analyses of hemp oil obtained from the two farms involved in the CS were performed to determine the oil composition, particularly in terms of fatty acids and antioxidant (notably of polyphenols and tocopherol compounds) contents. Relevance of the analysed contents was then compared with references available in literature.

\subsection{An exploration of strategic opportunities for organic hemp value chain development}

From March to June 2019 an exploratory study was carried out aiming at providing strategic information to Sicilian actors for further development of hempseed oil value chains. This study was not meant to be a systematic scientific analysis of the 
situation, but rather a tailored expertise-based investigation to provide key elements for enriching the co-innovation dynamic and the perspective of local actors. This exploration involved a benchmarking of prices for hemp oil in Europe according to packing and market positioning and a strategic exploration of possible industrial development pathways.

The benchmark was based on an online review of prices of four national markets (Italy, France, Belgium, Germany) that were highlighted by the Sicilian actors as the most interesting for exports. The industrial development pathways exploration relied on interviews with local actors in March 2019 and learnings from other hemp development stories from abroad (France $^{3}$, Belgium $^{4}$ ). Based on these inputs, we drew a global overview of strengths, weaknesses, opportunities and threats for the development of hemp-based products in Sicily based on a SWOT analysis (Pickton and Wright, 1998). We then explored more in details contrasting development scenarios that were built based on three types of hypotheses: acreage of hemp dedicated to food use (100 ha as current situation or above), type of processing capacity (small or large), location of processing units (a central one, many small ones, a foreign operator). Further details on the study methodology can be found in Antier et al. (2019). The study refers to organic products, as the involved case study actors operate under organic certification.

\section{Results}

\subsection{Barriers to hemp oil development in Sicily}

In accordance to the methodology described above, the main barriers to the development of hempseed oil production in Sicily have been identified. Furthermore, following the framework proposed by Morel et al. (2020), they were classified considering the appropriate level (or ring) of the hemp value chain they refer to. At the primary production level, the main identified barriers were:

- lack of technical knowledge and references: as hemp has not been cultivated for decades in Sicily at significant scale, crop-specific expertise (i.e. crop protection and fertilization techniques, role in rotation, optimal timing for sowing and harvesting) resulted unavailable;

- lack of economic knowledge and references: precise data about profitability of hemp are not easy to determine in an uncertain and vulnerable context;

- lack of information because of problems with advisory context: in Sicily, advisory services are weak and mainstream, so not involved in alternative/minor crops;

- lack of adapted cultivars suitable for the local context: relatively few cultivars are registered in the EU seed catalogue and available for purchase; most of them were bred for different environments and final uses (e.g. textiles, chemicals, paper, bioplastics, insulation) to those relevant for the CS; hemp seeds are generally imported from other European countries and available too late for local sowing conditions. The use of farm saved seeds represents an

\footnotetext{
${ }^{3}$ L'Chanvre (www.lchanvre.com); Ananda (www.anandaetcie.org).

${ }^{4}$ PurChanvre (www.purchanvre.be); Chanvre wallon (www.chanvre wallon.be).
}

option but this technique may increase THC level in the crop (see barriers about regulation);

- lack of knowledge about impacts of diversification on agroenvironmental performances: uncertainties exist about the extent in which integrating hemp into wheat-based rotations could enhance the agronomic and environmental performances of their practices;

- need of investment for adapted machinery: combine harvesters commonly used for wheat are unfit for harvesting fresh and tenacious hemp straws. The required investments are unjustified for the few ha of hemp cultivated by each farm;

- regulation impacting farmers: risks incurring in unknowingly selling hemp products with THC content above regulatory thresholds.

Moving toward the next levels, from harvest to retail, main barriers were:

- equipment for drying requires investment: dedicated dryers for hemp are needed but purchase is unjustified for the few hectares;

- equipment for processing requires investment: pressing machines to produce hemp oil require investment.

The market analysis then revealed a number of relevant shortcomings, namely:

- deficient market identification: hempseed oil currently relies on few mainstream commercial channels and lacks visibility in most outlets;

- difficult exploitation of alternative markets: hemp commercialization frequently occurs through e-commerce channels that are to date poorly developed in Italy.

Finally, as far as coordination between value chain actors is concerned, the barriers highlighted by our study were:

- no ensured quality of products to be bought, sold or to establish secure contracts: products' quality specifications are not yet defined thus limiting commercialization to short and local chains (e.g. direct sale);

- limited cooperation between innovative farmers: collective investments on machineries or the establishment of common marketing initiatives are thus far hampered.

\subsection{Performance indicators at rotational and single crop level}

The agroecological implications originating from the hemp integration in the farm rotation to assess the environmental profile of the crop in semi-arid conditions are reported in Figure 1. The performance assessment results obtained for both the reference and the diversified systems of the two selected hemp farms representative for the hemp Sicilian scenario are reported. The diversified system showed an improvement of the performances of EY, CDI, NBAL, FCFGHG and WOL for farm 1, while an improvement only for $\mathrm{CDI}$ and no significantly relevant changes $(< \pm 5 \%$ compared to the Reference system) for EY, ACI, BSO, and FCFGHG in farm 2. Conversely the ACI, PBAL, and BSO 


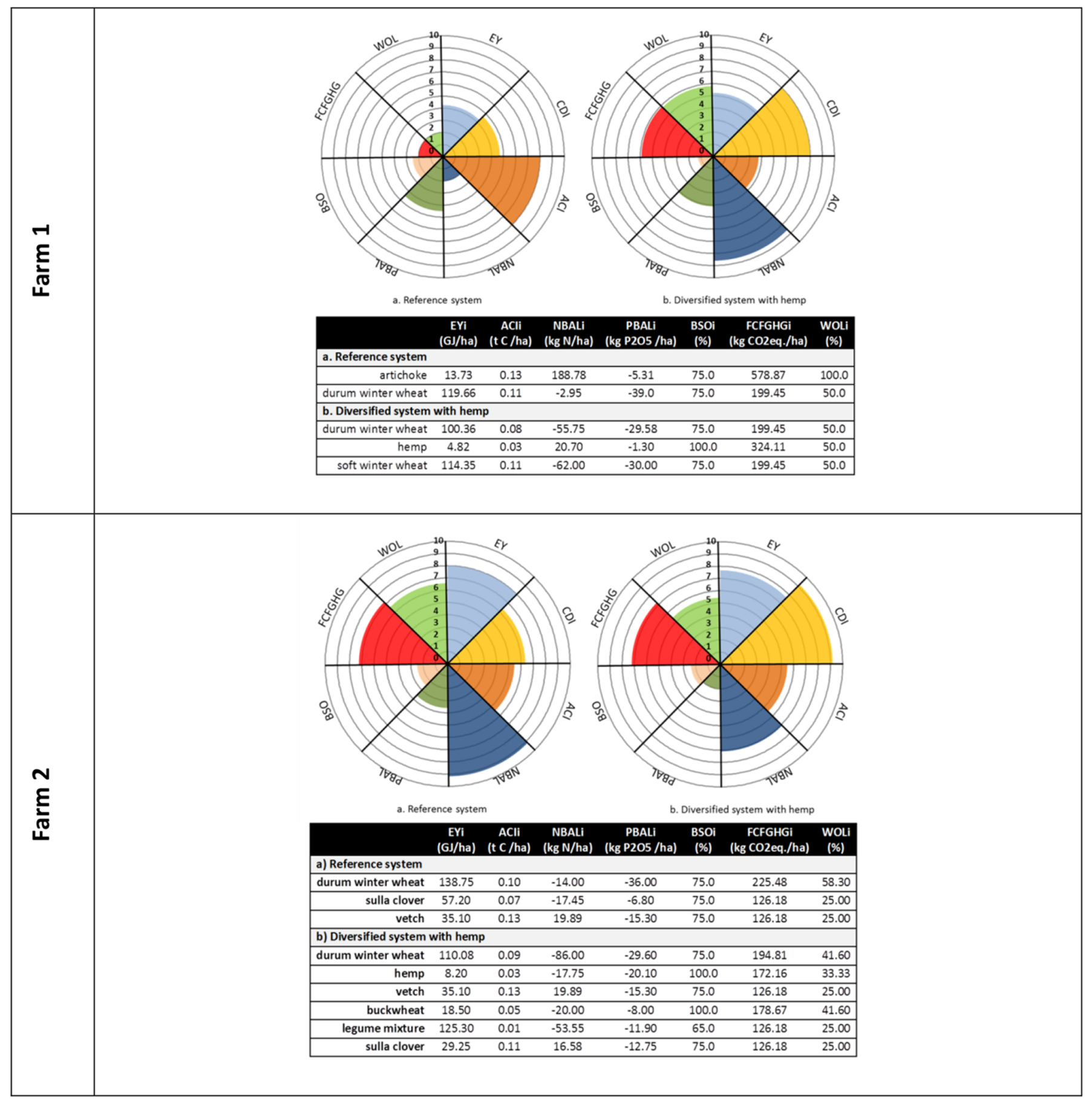

Fig. 1. Performance of farm 1 and farm 2 for (a) the reference and (b) the diversified system following the introduction of hemp in the cropping system. 
Table 2. Key chemical components of hempseed oils.

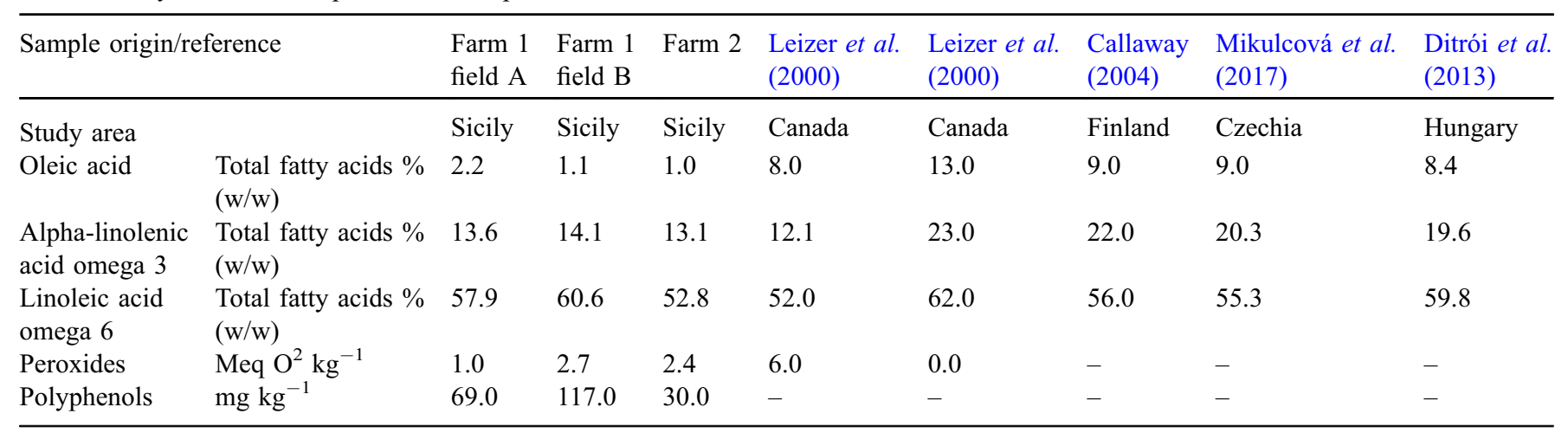

declined in farm 1; as none of the crops were fertilized after the organic conversion, NBAL and PBAL strongly decreased in farm 2 where WOL similarly decreased due to a greater workload in months (January-March) preceding the sowing of the two new spring crops (hemp and buckwheat).

Considering the single crop level, hemp strongly contributed to improve the nutrient balance of the diversified system in farm 1, while, compared to other crops, its introduction led to a greater leaching risk due to the reduction in soil coverage during the drainage period and to a decrease of soil carbon inputs since its aboveground residues were removed from the field by the farmer in consideration of their slow decomposition rate. Furthermore, hemp showed greater GHG emissions related to fuel consumption than the other crops of the diversified system caused by more frequent tillage operations from the harvest of the previous crop to the sowing of hemp. Farm 2, although characterized by slightly higher yields, showed a similar behaviour at single crop (hemp) level, except for the different nutrient balance (NBAL and PBAL) as the crop was not fertilized and for the lower warming potential due to less tillage carried out in this farm.

\subsection{Hempseed oil chemical characteristics}

Table 2 reports the values of the hempseed oil key chemical components of the two studied farms in comparison to the values obtained by other authors from studies carried out in different hemp cultivation areas. With the exception of the oleic acid, that was lower in the Sicilian origin oils compared to the values reported for different study areas, the relative contents of the alpha-linolenic and linoleic fatty acids resulted very similar to the equivalent oils. Moreover, peroxides values were particularly low (Leizer et al., 2000; Ditrói et al., 2013; Callaway, 2004; Mikulcová et al., 2017).

\subsection{Highlights of the exploration of hemp oil value chain development in Sicily}

\subsubsection{Benchmarking of prices for organic hemp oil}

In the explored countries, hemp oil is mainly sold on farms or via e-commerce and to a lesser extent in some specialised and mainstream supermarkets. There is no data available at the EU level on the share of each marketing channel. The study focused on online and on-farm direct selling prices as those two outlets were the ones mainly targeted by CS actors. Observed prices ranged from $26 €$ to $140 € / \mathrm{L}$ (Tab. 3) and varied significantly according to the packaging size (more than double price for small packaging in some cases) and to the product positioning (food, cosmetics or a double-use). The highest prices were reached through cosmetics marketing, while low priced products coming from Germany $(26 € / \mathrm{L})$ were identified.

\subsubsection{Industrial development pathways}

The main identified strengths, opportunities, weaknesses and threats of the development of hemp-based food products in Sicily are summarised in Table 4. Actors underlined the necessity to further acquire references on the profitability of hemp cultivation for producing oil. First raw estimations tended to show that profitability is potentially high. According to interviews with CS actors, from 1 ha of dried and cleaned hemp in Sicily, $80 \mathrm{~L}$ of oil and $320 \mathrm{~kg}$ of flour can be obtained on average (as local production is too recent, interannual variability can only be assumed, but not calculated). Based on a price of $50 € / \mathrm{L}$ for the oil and $15 € / \mathrm{L}$ for the flour (conservative direct selling prices), revenues were estimated at $9,600 € /$ ha. Considering estimations made by Frascarelli and Meloni (2018) that costs represent $60 \%$ of revenues, margin may reach $3,840 € /$ ha. Although more conservative assumptions and lower selling prices could be considered, the estimated margin was high and may have the potential to easily cover the investment in pressing machines whose prices vary from 1,000 to $2,000 €$ (small-scale pressing machine with capacity of 1 ton/day) to $40,000-65,000 €$ for intermediary machines 5 (capacity of 10 tons/day).

Although economic profitability should be further investigated, major challenges to local value chain development relate more to the structuration of actors for production and processing. Currently, the two farms participating in the case study cultivate about 5 ha each of hemp and support other farmers in hemp cultivation. Nowadays, one of these two farms owns pressing facilities that are used for processing hemp from other farms, too. If more farmers cultivate hemp for food production, a major question is whether the initial

\footnotetext{
${ }^{5}$ Estimations based on the website www.alibaba.com.
} 
Table 3. Indicative comparison of the price of organic hemp oil on a range of online- and on-farm direct-selling outlets.

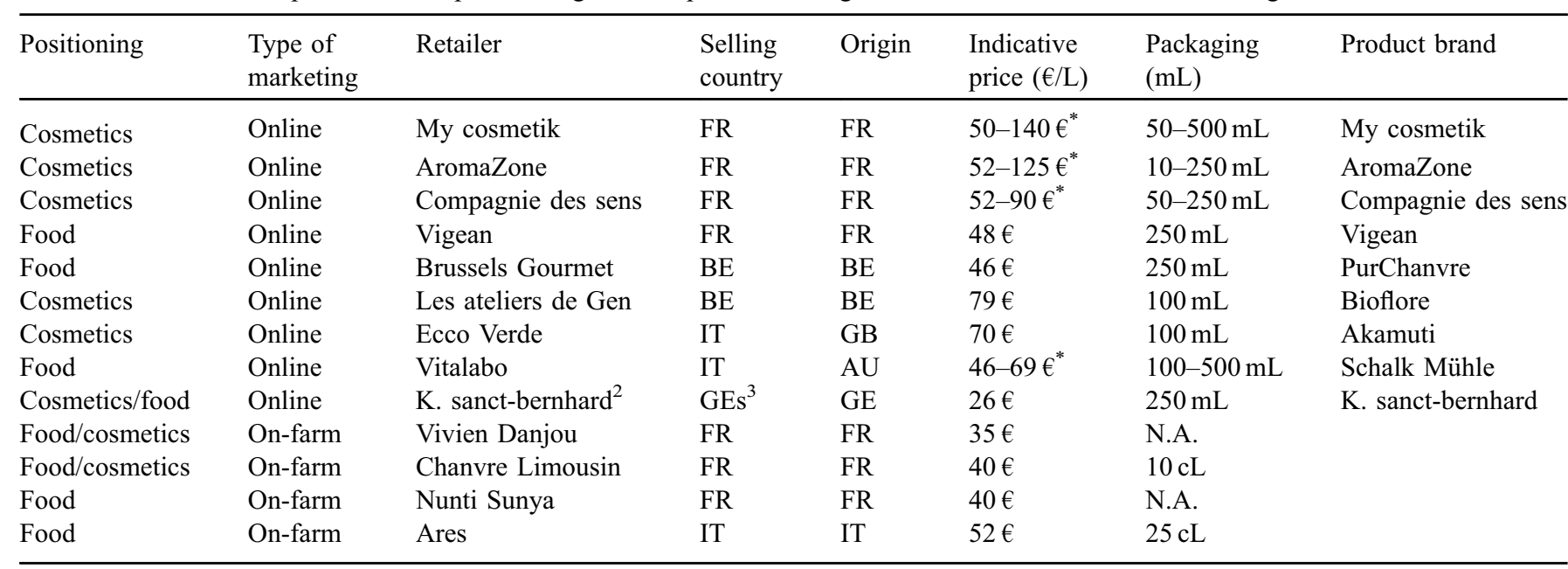

Notes: *depending on packaging size; ${ }^{2}$ Kräuterhaus sanct-bernhard; ${ }^{3}$ also FR, IT, GB. Websites: www.mycosmetik.fr; www.aroma-zone.com; www.compagnie-des-sens.fr; www.huilerievigean.com; www.rob-brussels.be; www.ecco-verde.it; www.lesateliersdegen.be; www.vitalabo.it; www.sanct-bernhard.fr; www.vivien-danjou.fr; www.chanvrelimousin.fr; www.nuntisunya.com; www.ares.farm.

Table 4. SWOT analysis of hemp-based food products in Sicily.

\section{Strengths \\ Relevant for crop diversification in wheat-based systems Relatively simple products already developed and tested Nutritional quality (proteins content, quality fats) Origin EU/Italy/Sicily \\ Potential capacity for quality differentiation versus imported products?}

\section{Opportunities}

Italian food culture includes pasta and oil consumption, making the potential market very large (although specific pasta and oil still represents a change in habits)

Tourism = interest for local, high quality products

\begin{abstract}
Weaknesses
Still some confusion in consumers' mindset (drug versus food) $\rightarrow$ requires a certain investment in communication Still limited local processing capacity (but local actors are interested in investing)

Coordination and strategic orientation of the sector not yet structured
\end{abstract}

\section{Threats}

Countries with large production are very competitive (eastern Europe, Canada, China)

Risk of competition versus coordination in the territory Growth of the acreage may lead to increased pest pressure ${ }^{8}$

\footnotetext{
${ }^{8}$ According to O'Brien and Arathi (2019), as cultivation of hemp continues to expand, insect pests on hemp could become prevalent.
}

pioneers in hemp production will keep the role of centralising the processing, acting as hubs for others, or whether new processing facilities will be created or processing externalized. Different development pathways are presented in Table 5. Pathway I1 is related to a stable acreage of hemp for food around 100 ha (current situation) and implies only one small processing capacity in the region. Pathway I2 illustrates a larger target acreage, processed through one large processing capacity. Pathway I3 illustrates an alternative choice of having several small processing capacities. Finally, pathway I4 illustrates the option of externalizing the processing.

\section{Discussion}

To investigate and support the development of organic hempseed oil in Sicily, we took on an action-research perspective with a broad value chain approach, leading to the identification of priority areas for targeted actions intended to enable both further research findings and concrete practitioners' strategies. To this aim, the initial exploration of barriers to hemp development, that confirmed that barriers occur at different levels, was instrumental to the definition of a tailored action plan that combines initiatives at farming, mechanisation, processing and governance scales, which are discussed below and summarized in Table 6. These different actions concur and are conducive to a harmonised development plan aiming to (re)orient the Sicilian organic farms' market choices towards locally constructed value chains, considering the concomitant reduction in market interest for more traditional crops.

\subsection{Tackling informational and technical barriers at farm level}

To achieve a greater diversified strategy where hemp may play a relevant role, new competences are needed, notably at agroecological level: role in rotation, cultivars suitability, fertilization, water stress resilience, farming technique are among the areas where specific expertise has to be developed 
Table 5. Exploratory analysis of contrasting development pathways for organic hemp oil production in Sicily.

\begin{tabular}{|c|c|c|c|c|c|}
\hline & Description & Advantages, strengths & $\begin{array}{l}\text { Risks, threats, } \\
\text { challenges }\end{array}$ & Context factors & Governance \\
\hline Pathway I1 & $\begin{array}{l}\text { Acreage }=100 \text { ha }+1 \\
\text { small processing } \\
\text { capacity }\end{array}$ & $\begin{array}{l}\text { Single stream, Single } \\
\text { point of contact }\end{array}$ & $\begin{array}{l}\text { Reliability of the } \\
\text { unique processing } \\
\text { capacity and its owner }\end{array}$ & $\begin{array}{l}\text { Given the estimated } \\
\text { market size, acreage } \\
\text { could most likely be } \\
\text { increased above } \\
100 \text { ha }\end{array}$ & $\begin{array}{l}\text { Centralized entity for } \\
\text { processing, and the } \\
\text { different farmers } \\
\text { could set up a } \\
\text { representation entity }\end{array}$ \\
\hline Pathway I4 & $\begin{array}{l}\text { Acreage over } \\
100 \text { ha }+ \text { external } \\
\text { foreign processor }\end{array}$ & $\begin{array}{l}\text { Simplicity } \\
\text { No additional } \\
\text { workload }\end{array}$ & $\begin{array}{l}\text { Not so local } \\
\text { Dependency on } \\
\text { processors prices }\end{array}$ & $\begin{array}{l}\text { Highly dependent on } \\
\text { the price of } \\
\text { transportation } \\
\text { Location of } \\
\text { processors? }\end{array}$ & Market rules mainly \\
\hline
\end{tabular}

and shared for a firmer crop establishment in Sicily. To tackle these technical barriers the case study promoted seminars and field days bringing specific know-how in Sicily from areas with greater familiarity with hemp. Moreover, to more substantially progress in this technical area further support has been mobilized by the case study's multi-actor group through both a national research project (UNIHEMP $^{6}$, focusing on hemp uses in the bioeconomy domain and also covering cultivars testing, thus potentially broadening the choice for Sicilian hemp farmers) and an Operational Group for innovation on local food chains for hemp oil and flour. Both initiatives should corroborate expertise on the crop, investigate conditions for economic optimization of on-farm and downstream activities and test new machinery introduction, finally providing insights on actual improvements for the up-scaling of hemp cultivation and value chains.

\subsection{Addressing agro-environmental shortcomings}

Our agro-environmental assessment in Sicily demonstrated that hemp offers no magic sustainability bullet being its performances (especially those related to the greenhouse gas emissions from fuel consumption) context-dependent as they can vary among farms in relation to the adopted cultivation techniques. Consequently, the introduction of hemp in a cereal crop rotation has to be factually evaluated in each situation.

\footnotetext{
$\overline{{ }^{6} \text { See: http://unihemp.dhitech.it/. }}$
}

However, room for improvements in the direction of a greater agroecological compatibility has been identified in the course of the dialogue between researchers and actors, once taking stock of the performance assessment results. Hemp is characterized by low $\mathrm{N}$ requirement, as also highlighted by Tang et al. (2017). Its introduction in a cereal-based cropping system can improve $\mathrm{N}$ balance at rotational level especially in low input organic farming conditions and fertilisation plans can be designed accordingly. Furthermore, Amaducci et al. (2008a) reported that hemp improves soil structure thanks to its deep root system and to the large amount of biomass left in the field. In our CS, hemp residues were removed from the field by both farmers due to their slow decomposition rate. As this practice caused a low performance in relation to the contribution hemp may provide in increasing the soil organic carbon content, chopping of residues was deemed suitable once proper mechanical devices are deployable.

Hemp is a spring crop with a relatively short growing cycle that allows subsequent seeding of a winter cereal. Hemp is generally introduced in a cereal-based rotation before winter wheat to exploit its known ability to suppress weeds during the following cash crop cycle (Zegada-Lizarazu and Monti, 2011). This strategy was also followed by the two Sicilian farmers who confirmed that hemp is a remarkable predecessor for winter wheat in rainfed Mediterranean environments, despite that the performance indicators did not capture the specific weed containing capacity. The apparent conflict between empirical evidence and the performance assessment results 
Table 6. Research and action interventions to support organic hemp development in Sicily based on initial analysis of barriers at the value chain level.

\begin{tabular}{l}
\hline Value chain level \\
\hline Lack of technical knowledge and references \\
Lack of economic knowledge and references \\
Lack of information because of problems with \\
advisory context \\
Lack of adapted plant varieties in the local \\
context
\end{tabular}

Agricultural

production

Lack of knowledge about impacts of diversification on agro-environmental performances

Need of investment for adapted machinery

Regulation impacting farmers

Equipment for drying requires investment

From harvest to retail

Equipment for processing requires investment

\section{Coordination}

between value chain actors

Market

\begin{abstract}
No ensured quality of products to be bought, sold or to establish secure contracts

Limited or no cooperation between innovative farmers

Uncertain or unstable market
\end{abstract}

DiverIMPACTS CS interventions

Critical expertise attracted from other Italian regions for two farm days in 2018 and 2019, mobilizing local stakeholders to benefit from it A study was commissioned and performed to analyse the crop profitability

Consultancies activated from national hemp expert

Interaction with the national $6.7 \mathrm{mln} €$

UNIHEMP project to stimulate breeding for Sicilian environment

Interaction with the Ministry of Agriculture getting permission for farm seed reuse Assessment performed to analyse hemp-specific validity in rain-fed crop rotations

An Operational Group (OG) is being set up with critical participation of various CS players to explore machinery investment

THC content chemical analyses to make sure produce is within regulatory limits

Dedicated dryers use and costs will be economically assessed by the dedicated OG A small capacity pressing machine will be tested in the abovementioned $\mathrm{OG}$ N.A.

The OG will enable cooperation among partners and additional stakeholders

The DiverIMPACTS benchmarking offered Sicilian hemp actors valuable indications on how to market hemp products will receive further and more in-depth scrutiny in the course of the case study.

Our study also highlighted that the hemp introduction into a cereal-based rotation increases the number of months in which the soil is bare (in particular from the harvest of the previous winter crop in June-July until the sowing of hemp in March-April) thus leading to an increased potential risk of nitrate leaching and erosion. The introduction of a proper cover crop during this period to increase soil coverage and to catch radiation as well as nutrients has been debated and is intended to be tested on-farm.

The interaction between genotype and environment, in particular day-length, water and temperature, has a significant effect on hemp productions (Salentijn et al., 2019; Amaducci et al., 2008b). In this respect, the Futura 75 cultivar used by both farmers seems not to perform well in terms of energetic yields compared to others. Further hemp cultivars will be considered to improve seed yields, also valuing opportunities arising from the national UNIHEMP research project.

\subsection{Understanding the nutraceutical and taste lever}

The fatty acids content may vary considerably with cultivar, climate, growing conditions and harvesting period.
Seed maturity also effects the fatty acids composition: the more mature the seeds the higher is the percentage of unsaturated fatty acids and the lower the percentage of saturated ones (Ross et al., 1996). Accordingly, sampled hempseed oil characteristics did not present critically different values vis-à-vis non-Sicilian hemp oil composition. Nevertheless, hempseed oil nutritional profile allows to use a variety of nutrition claims related to its fatty acids content, such as "having a high content of omega-3 fatty acids" (at least $0,6 \mathrm{~g}$ of alpha-linolenic acid per $100 \mathrm{~g}$ of product) and being "high in polyunsaturated fat" ( $45 \%$ of the fatty acids present in the product derive from polyunsaturated fat). These nutritional aspects could be valued by consumers. Moreover, organic hemp-based foods could enjoy a more favourable attitude among consumers who tend to have greater explorative behaviours, informed diets and supportive attitudes for territorialised products, thus rewarding innovative value chains (Rana and Paul, 2017). These advantages represent levers for marketing.

Finally, for two consecutive years (2018 and 2019), farm 1 was awarded as best Italian hempseed oil by the University of Naples Federico II. In 2018, the oil was acknowledged as having hints of liquorice on the palate and particularly pleasant 
to the taste with "notes of fresh grass, walnut, bread crust and hay and absence of fermentation and oxidative defects"? These awards proved to be very powerful marketing hooks for the farm. Moreover, the selection of cultivars suitable for the Sicilian pedological and climate contexts and the contextual optimisation of small processing plants could improve the biochemical oil composition and its taste thus representing an interesting marketing opportunity (Aluigi and Viganò, 2016).

\subsection{Targeting value chains}

The results of the marketing and value chain development exploration were presented to CS actors who gained a broader understanding of the competitive conditions in European markets and reflected on the possibilities for scaling up Sicilian hempseed oil value chains. Those discussions underlined that to figure out room for hemp value chain scalability, further research and practice are necessary to deal with issues in the areas of proper investment rhythm (more incremental or fast), service provision (processors) or integration (food company) for agro-industrial scalability, market positioning and scenarios for the Sicilian hempseed oil. The setting up of an Operational Group consecrated to the development of hemp-based food value chains and operated by a subset of the CS group may provide conditions for implementing innovative value chain and organisational configurations that may also generate a suitable testing ground for the Sicilian organic hemp development pathways described in Section 3.4.

\subsection{Dealing with a constraining socio-political climate}

Recent evidence of the erratic political and juridical climate surrounding hemp in Italy still induces cautious attitudes among operators. Despite a recent legislative evolution (Law, 2016/242) regulating the cultivation, transformation and sale of hemp and hemp derived products, some uncertainties persist among Italian operators. Cultivation is considered legal if the level of THC remains below the threshold of $0.2 \%$ of the raw hemp, with a tolerance up to $0.6 \%$, and farmers that grow cultivars registered in the seed catalogue, showing evidence of the seed purchase, would be considered non-responsible for the possible THC escalation beyond that regulatory perimeter (that would anyway preclude the produce selling). This particularly applies to farm saved seeds for which a possible THC level increase is expected. As the case study already faced agronomic problems in relation to a late availability of seeds and seed saving has been considered a viable option to test more timely sowings, the case study has engaged a dialogue with the Ministry of Agriculture to get written permission for seed reuse as a derogation attributed to a research project, which was finally conceded with limitations to less than one hectare for each case study farm.

\section{Conclusion}

Unlocking the organic hemp potential in Sicily in a coinnovation perspective and embracing the whole value chain is

\footnotetext{
${ }^{7}$ From the panel test of the Department of agriculture of University of Naples Federico II (2018).
}

a promising way to foster opportune industrial development pathways for which a consensus among operators has to be built, in a situation where hemp value chains still attract some concern at socio-political level. Minimising THC content far below regulatory limits and offering objective and perceived advantages at nutritional level, foods derived from the plant are increasingly appearing on the market, although at niche scale. In a somewhat moderated scenario based on substantial barriers removal or adaptation, hemp foods profitability should remain significantly higher than for other value chains, potentially attracting more operators and thus facilitating the expertise spread and the achievement of a critical mass of produce that may further reduce operative and transaction costs.

Acknowledgements. This work was funded by the DiverIMPACTS - Diversification through Rotation, Intercropping, Multiple Cropping, Promoted with Actors and value-Chains towards Sustainability - research and innovation project within the framework of H2020 call "Rural Renaissance - Fostering innovation and business opportunities", under Grant Agreement No. 727482

The Authors thank and acknowledge the support received by: Philippe Barret (Université de Louvain-la-Neuve) in the study exploring the development potential of a Sicilian hemp value chain; the Sammartino and Gioia farm families for the kind availability in sharing pioneering knowhow on hemp cultivation and processing and for co-leading experimental activities; Massimo Palumbo and Nino Virzì (CREA, Research Centre for cereal and industrial crops) for their experience sharing in crop diversification in semi-arid conditions.

Conflicts of interest. The authors declare no conflict of interest. This paper is the result of teamwork. L.C., K.M. and G.D.G. conceived the research question and the research design. All authors analysed the data and discussed the results. L.C., K.M. and G.D.G. wrote the paper with contribution for 2.2,3.2 and 4.2 by I.I. and S.C. as well as for 2.4, 3.4 and 4.4 by C.A., further to their critical revision. All authors have read and agreed to the published version of the manuscript.

\section{References}

Aluigi D, Viganò E. 2016. La canapa come opportunità di sviluppo per le imprese agricole. Agriregionieuropa 12(45), in Italian.

Amaducci S, Zatta A, Raffanini M, Venturi G. 2008a. Characterization of hemp (Cannabis sativa L.) roots under different growing conditions. Plant Soil 313: 227-235. https://doi.org/10.1007/ s11104-008-9695-0.

Amaducci S, Colauzzi M, Bellocchi G, Venturi G. 2008b. Modelling post-emergent hemp phenology (Cannabis sativa L.): theory and evaluation. European Journal of Agronomy 28(2): 90-102.

Antier C, Morel K, Colombo L, Dara Guccione G, Baret P. 2019. Exploring the potential of value chains for Sicilian hemp-based food products. Report. Zenodo. https://doi.org/10.5281/zenodo.3477906.

AUSAID. 2005. Ausguidelines: the logical framework approach. Australia: Australian Agency for International Development, pp. 41.

Baldini M, Ferfuia C, Piani B, et al. 2018. The performance and potentiality of monoecious hemp (Cannabis sativa L.) cultivars as a multipurpose crop. Agronomy 8: 162. https://doi.org/10.3390/ agronomy 8090162.

Bos AP, Grin J. 2012. Reflexive interactive design as an instrument for dual track governance. System innovations, knowledge 
regimes, and design practices towards transitions for sustainable agriculture. Paris: INRA-SAD.

Callaway JC. 2004. Hempseed as a nutritional resource: an overview. Euphytica 140: 65-72.

Coldiretti. 2019. Canapa, cosa cambia dopo la sentenza della Cassazione. Il Punto: Coldiretti. https://www.ilpuntocoldiretti.it/ attualita/ambiente/canapa-cosa-cambia-dopo-la-sentenza-dellacassazione/ (last consult: 21st June).

Chevalier JM, Buckles DJ. 2019. Participatory action research: theory and methods for engaged inquiry. Routledge.

David PA. 1985. Clio and the economics of QWERTY. The American Economic Review 75(2): 332-337.

de Magistris T, Gracia A. 2008. The decision to buy organic food products in Southern Italy. British Food Journal 110(9): 929-947.

Ditrói K, Kleiner D, Böszörményia A, Szentmihályib K, Fébel H. 2013. The alimentary impact of the hemp seed. Acta Alimentaria 42(3): 410-416. https://doi.org/10.1556/AAlim.42.2013.3.14.

Eisenhardt KM. 1989. Building theories from case study research. Academy of Management Review 14(4): 532-550.

Elo S, Kyngäs H. 2008. The qualitative content analysis process. Journal of Advanced Nursing 62(1): 107-115.

Elzen B, Barbier M, Cerf M, Grin J. 2012. Stimulating transitions towards sustainable farming systems. In: Farming systems research into the 21st century: the new dynamic. Springer, pp. 431-455.

Foti VT, Scuderi A, Bellia C. 2019. Actuality and future prospects of Cannabis sativa L. crops. Features and problems. Quality-Access to Success 20(S2): 255-262, ISSN: 15822559.

Frascarelli A, Meloni C. 2018. Canapa per uso alimentare, una soluzione che rende. L'Informatore Agrario 30: 46-49.

Geels FW, Schot J. 2007. Typology of sociotechnical transition pathways. Research Policy 36(3): 399-417.

Grin J, Rotmans J, Schot J. 2010. Transitions to sustainable development: new directions in the study of long term transformative change. Routledge, $418 \mathrm{p}$.

ISTAT database. http://dati.istat.it/Index.aspx?DataSetCode= DCSP_COLTIVAZIONI, in Italian (last consult: 02 July 2020).

Klerkx L, Aarts N, Leeuwis C. 2010. Adaptive management in agricultural innovation systems: the interactions between innovation networks and their environment. Agricultural Systems 103(6): 390-400.

Law 2016/242 of the 2nd December. Provisions for the promotion of cultivation and the agro-industrial chain of hemp (16G00258). Official Journal of Italian Republic, general series, n. of the 30th December 2016, in Italian.

Leizer C, Ribnicky D, Poulev A, Dushenkov S, Raskin I. 2000. The composition of hemp seed oil and its potential as an important source of nutrition. Journal of Nutraceuticals, Functional \& Medical Foods 2(4): 2000.

Lin BB. 2011. Resilience in agriculture through crop diversification: adaptive management for environmental change. BioScience 61 (3): 183-193.

Lundgren JG, Fausti SW. 2015. Trading biodiversity for pest problems. Science Advances 1: e1500558.

Magrini M-B, Anton M, Cholez C, et al. 2016. Why are grain-legumes rarely present in cropping systems despite their environmental and nutritional benefits? Analyzing lock-in in the French agrifood system. Ecological Economics 126(Suppl. C): 15262.

Meynard J-M, Charrier F, Fares M, et al. 2018. Socio-technical lockin hinders crop diversification in France. Agronomy for Sustainable Development 38(5): 54.
Meynard J-M, Jeuffroy M-H, Le Bail M, Lefèvre A, Magrini M-B, Michon C. 2016. Designing coupled innovations for the sustainability transition of agrifood systems. Agricultural Systems. https://doi.org/10.1016/j.agsy.2016.08.002.

Mikulcová V, Kašpárková V, Humpolícek P, Bunková L. 2017. Formulation, characterization and properties of hemp seed oil and its emulsions. Molecules 22: 700. https://doi.org/10.3390/mole cules22050700.

Miles MB, Huberman AM. 1984. Qualitative data analysis: a sourcebook of new methods. Beverly Hills, CA: Sage.

Ministry of Health. 2000, Decree 4th November 2019. Definition of maximum levels of tetrahydrocannabinol (THC) in food. Official Journal of Italian Republic, general series, n. 11 of the 15 th January 2020, in English at: https://cannabislaw.report/italyministry-of-health-decree-definition-of-maximum-levels-of-tetra hydrocannabinol-thc-in-food/.

Morel K, Revoyron E, San Cristobal M, Baret PV. 2020. Innovating within or outside dominant food systems? Different challenges for contrasting crop diversification strategies in Europe. PLOS ONE $15(3)$.

O'Brien C, Arathi HS. 2019. Bee diversity and abundance on flowers of industrial hemp (Cannabis sativa L.). Biomass and Bioenergy 122: 331-335.

Pickton DW, Wright S. 1998. What's swot in strategic analysis? Strategic Change 7(2): 101-109.

Rana J, Paul J. 2017. Consumer behavior and purchase intention for organic food: a review and research agenda. Journal of Retailing and Consumer Services 38: 157-165.

Ross SA, EISohly HN, ElSayeda EIKashoury A, ElSohly MA. 1996. Fatty acids of cannabis seeds. Phytochemical Analysis 7: 279-283.

Salentijn EMJ, Petit J, Trindade LM. 2019. The complex interactions between flowering behavior and fiber quality in hemp. Frontiers in Plant Science 10. https://doi.org/10.3389/fpls.2019.00614.

Sapino S, Carlotti M, Peira E, Gallarate M. 2005. Hemp-seed and olive oils: their stability against oxidation and use in $\mathrm{O} / \mathrm{W}$ emulsions. Journal of Cosmetic Science 56: 227-251. https://doi. org/10.1111/j.1467-2494.2005.00290.

Siggelkow N. 2007. Persuasion with case studies. Academy of Management Journal 50(1): 20-24.

SINAB. 2019. Bio in cifre. Anticipazioni, MIPAAFT, ISMEA and CIHEAM.

Tang K, Struik PC, Yin X, et al. 2017. A comprehensive study of planting density and nitrogen fertilization effect on dual-purpose hemp (Cannabis sativa L.) cultivation. Industrial Crops and Products 107: 427-438. https://doi.org/10.1016/j. indcrop.2017.06.033.

Vanloqueren G, Baret PV. 2008. Why are ecological, low-input, multi-resistant wheat cultivars slow to develop commercially? A Belgian agricultural 'lock-in' case study. Ecological Economics 66(2): 43646.

Van Mierlo BC, Regeer B, van Amstel M, et al. 2010. Reflexive monitoring in action. A guide for monitoring system innovation projects. Communication and Innovation Studies, WUR. VU: Athena Institute.

Zegada-Lizarazu W, Monti A. 2011. Energy crops in rotation. A review. Biomass Bioenergy 35: 12-25. https://doi.org/10.1016/ j.biombioe.2010.08.001.

Cite this article as: Colombo L, Guccione GD, Canali S, Iocola I, Antier C, Morel K. 2020. An action-research exploration of value chain development from field to consumer based on organic hempseed oil in Sicily. OCL 27: 56. 